Research Article

\title{
Study of Effectiveness of IDRS as a Screening tool in OPD attending Adults at a Medical College Hospital in Central India
}

\section{Priyanka Barjatya' Badri Narayan Mishra ${ }^{2}$, Naveen Kumar Singh Panwar ${ }^{3}$, DS Chouhan ${ }^{4}$}

${ }^{1,3}$ P.G. Second Year, ${ }^{2}$ Professor, ${ }^{4}$ Statistician cum Asst. Professor, Dept. of Community Medicine, Ruxmaniben Deepchand Gardi Medical College, Ujjain. M.P., India.

DOI: https://doi.org/10.24321/2394.6539.201908

\section{I $\quad \begin{array}{lllll}\mathbf{N} & \mathbf{F} & \mathbf{O}\end{array}$}

\section{Corresponding Author:}

Badri Narayan Mishra, Dept. of Community Medicine, Ruxmaniben Deepchand Gardi Medical College, Ujjain. M.P., India.

E-mail Id:

icaaicon2012@gmail.com

Orcid Id:

https://orcid.org/0000-0001-6956-0469

How to cite this article:

Barjatya P, Mishra BN, Panwar NKS, Chouhan DS. Study of Effectiveness of IDRS as a Screening tool in OPD attending Adults at a Medical College Hospital in Central India. J Adv Res Med Sci Tech 2019; 6(3\&4): 19-24.

Date of Submission: 2020-02-24

Date of Acceptance: 2020-03-23

\section{$\begin{array}{llllllll}\mathbf{A} & \mathbf{B} & \mathbf{S} & \mathbf{T} & \mathbf{R} & \mathbf{A} & \mathbf{C} & \mathbf{T}\end{array}$}

Introduction: Type 2 Diabetes Mellitus (T2DM) has established itself as a silent pandemic with devastating multiorgan involvement. The only way forward is to nip it at its bud by proactive screening at every available circumstance. There are many types of cost-effective screening tools available at national and international level. Indian Diabetic Risk Score (IDRS) developed by Madras Diabetes Research Foundation (MDRF) is one of them. The sensitivity of this simple non-invasive tool has been studied mostly in the Southern part of India.

Aim: To study the screening accuracy of the IDRS among Outpatient (OPD) attending adults at a tertiary health care setup.

Objective: To screen the OPD attending adults aged between $18-60$ years for risk of T2DM by IDRS score and check its sensitivity and specificity by univariate, bivariate and Receiver Operating Characteristic (ROC) Curve analysis taking Random Blood Sugar (RBS) as control.

Method: A cross-sectional study was carried out on OPD attending patients at a Medical college in central India. A total of 101 subjects were screened over a one-month period by purposive sampling method and their pertinent sociodemographic information along with RBS was collected in addition to IDRS data. Data coding and analysis was done in SPSS version 20.

Result: The participants mean age was $38.65 \pm 12.54)$, literacy rate at (63;62.4\%).and male representation at 56 (56.5\%). The prevalence of high risk, moderate risk and low risk for diabetes among participants as per IDRS were found to be $19.8 \%, 55.4 \%$ and $24.8 \%$ respectively. 11 subjects (10.89\%) recorded a RBS levels $\geq 140 \mathrm{mg} / \mathrm{dl}$. The area under the ROC curve was in the acceptable range (.7-.8). Fixing the IDRS core $\geq 35$ (moderate risk zone) the predicted risk of T2DM had a sensitivity of $90 \%$ and specificity of $64 \%$.

Conclusion: IDRS may be considered as a viable screening method for OPD attending patients in central India for risk evaluation in asymptomatic cases.

Keywords: T2DM, IDRS, Screening, Central Indian Medical College 


\section{Introduction}

The prevalence of diabetes mellitus is on rise all over the world, however, India is deemed as diabetic capital of the world with the rise in its burden which is expected to rise to 100 million by $2030 .{ }^{1}$ The global prevalence of diabetes among adults belonging to the age group of more than 18 years has increased significantly from $4.7 \%$ in 1980 to $8.7 \%$ in $2015 .^{2,3}$ Every fifth diabetic in the world is an Indian. According to the International diabetic federation, India has approximately 72 million diabetics with an adult prevalence of $8.8 \%$ (2017) which is expected to double to 134 million with an expected adult prevalence of $11.4 \%$ by $2045 .{ }^{4}$

In India, the majority of people suffering from diabetes are unaware of their diabetic status since the disease is asymptomatic in its early stage, thus these patients do not seek treatment. Unfortunately, when they start seeking healthcare the disease is already in late pathogenesis phase with its dreaded complications looming large at their face..$^{5,6}$

Multiple scientific works ${ }^{7,8,9,10}$ of the literature suggest that by the time patients are diagnosed as diabetic, they have already developed subclinical atherosclerosis the unequivocal predecessor' of complications. Hence diagnosing diabetes at an early stage is of utmost importance. This will be possible when all available opportunities for screening are capitalized by a 'participant and worker-friendly, noninvasive and costeffective screening tool'. ${ }^{11,12}$ On this regards different diabetic societies have developed their own tools. IRDS is one such tool developed by Madras Diabetes Research Foundation (MDRF) and is derived based on the largest populationbased study on diabetes in India 'The Chennai Urban Rural Epidemiology Study' (CURES) keeping the Indian population in mind. ${ }^{4}$ Though it has been widely studied in Southern India its validation in other parts of the country needs to be done so as to give it a national acceptance. Here we have tried to test IDRS in a tertiary care hospital attending OPD population in central India.

We have aimed at evaluating the IDRS as a screening tool at a tertiary health care setup in the adult population.

Our objective was to screen the OPD attending adult population (18-60 years) for assessment of the risk of developing T2DM by IDRS score, to find sociodemographic associates, and estimation of odd's for Obesity (BMI), Hypertension and RBS with IDRS scores and finally validated its sensitivity and specificity by ROC curve analysis. The study had clearance from the institutional ethical committee of R.D. Gardi Medical College, Ujjain( M.P.), IEC Ref No-5/2019.

\section{Methodology}

This cross-sectional study was conducted at the teaching hospital of a Medical College in central India over a period of 1 month i.e. from $1^{\text {st }}$ May 2019 to $30^{\text {th }}$ May 2019. All the participants in the age group of 18 to 60 years attending the study setting constituted the study population and those who provided valid written consent during the specified time were considered as the study sample. All inclusive time bound sampling method was adopted meeting $10 \%$ criteria based on previous year OPD attendance from the selected OPD.Critically ill patients and pregnant ladies were excluded. A total of 101 participants fulfilling the inclusion criteria provided complete information and included for data coding and final analysis.

Table I.IDRS scoring and grading

\begin{tabular}{|c|c|c|}
\hline \multicolumn{2}{|r|}{ Particulars } & Score \\
\hline \multirow{3}{*}{ Age (years) } & $<35$ & 0 \\
\hline & $35-49$ & 20 \\
\hline & $\geq 50$ & 30 \\
\hline \multirow{3}{*}{$\begin{array}{l}\text { Abdominal } \\
\text { obesity }\end{array}$} & $\begin{array}{l}\text { Waist }<80 \mathrm{~cm} \text { [female] } \\
\quad<90 \mathrm{~cm} \text { [male] }\end{array}$ & 0 \\
\hline & $\begin{array}{l}\text { Waist } \geq 80-89 \mathrm{~cm} \text { [female], } \\
\quad \geq 90-99 \mathrm{~cm} \text { [male] }\end{array}$ & 10 \\
\hline & $\begin{array}{l}\text { Waist } \geq 90 \mathrm{~cm} \text { [female], } \\
\quad \geq 100 \mathrm{~cm} \text { [male] }\end{array}$ & 20 \\
\hline \multirow{3}{*}{$\begin{array}{l}\text { Physical } \\
\text { activity }\end{array}$} & $\begin{array}{c}\text { Exercise [regular] + strenuous } \\
\text { work }\end{array}$ & 0 \\
\hline & $\begin{array}{c}\text { Exercise [regular] or strenuous } \\
\text { work } 20\end{array}$ & 20 \\
\hline & No exercise and sedentary work & 30 \\
\hline \multirow{3}{*}{$\begin{array}{l}\text { Family } \\
\text { History }\end{array}$} & No family history & 0 \\
\hline & Either parent & 10 \\
\hline & Both parents & 20 \\
\hline \multicolumn{2}{|r|}{ Minimum score } & 0 \\
\hline \multirow{3}{*}{$\begin{array}{l}\text { Maximum } \\
\text { score (100) }\end{array}$} & No risk & $<30$ \\
\hline & Moderate risk & $30-50$ \\
\hline & High risk & $>60$ \\
\hline
\end{tabular}

Information regarding sociodemographic profile such as age, gender, marital status, education, family type and socioeconomic status was obtained from all the participants. Height and weight were recorded for calculating BMI. A digital weighing scale with accuracy up to 100 grams was used to measure weight. The weighing scale was adjusted to 0.0 and the participants were weighed with minimal clothing. Standing height was measured using a stadiometer with a fixed vertical backboard and an adjustable headpiece. Resting Blood Pressure (BP) both systolic and diastolic were measured by mercury standing sphygmomanometer and RBS was measured by glucometer for all the participants and findings thus obtained were recorded. IDRS consisting of four simple parameters namely age, abdominal obesity, family history of diabetes and physical activity, was calculated 
for individual patients. The scoring pattern and risk grading for IDRS is presented in Table 1.

\section{Statistical Analysis}

Data was compiled using MS excel and analyzed by using IBM SPSS software version 20. Continuous data were expressed as mean and standard deviation. The categorical data were expressed as a percentage and $\chi 2$ test was used wherever applicable. Univariate and bivariate analysis along with ROC curve analysis was employed for drawing an inference. p-value $<0.05$ was considered as the cut-off for drawing statistical inference.

\section{Result}

For 101 participants the mean age was $38.65 \pm 12.5$ years. The estimated prevalence (RBS levels $\geq 140 \mathrm{mg} / \mathrm{dl}$ ) of diabetes in the participants was $10,1 \%$. As per IDRS score, $19.8 \%$, $55.4 \%$ and $24.8 \%$ of the participating population belonged to respective high risk, moderate risk and low-risk category for developing T2DM.

Table 2.Profile and univariate analysis of IDRS with respect to sociodemographic, anthropometric and biochemical variables

\begin{tabular}{|c|c|c|c|c|c|c|c|}
\hline & & \multicolumn{4}{|c|}{ IDRS } & \multirow{3}{*}{ Chi-square } & \multirow{3}{*}{ p-value } \\
\hline & & \multicolumn{2}{|c|}{ low+moderate risk } & \multicolumn{2}{|c|}{ high risk } & & \\
\hline & & $\mathbf{N}$ & $\%$ & $\mathbf{N}$ & $\%$ & & \\
\hline \multirow{2}{*}{ Age (years) } & $<35$ & 33 & $40.7 \%$ & 0 & $0.0 \%$ & \multirow{2}{*}{12.10} & \multirow{2}{*}{0.001} \\
\hline & $35-60$ & 48 & $59.3 \%$ & 20 & $100.0 \%$ & & \\
\hline \multirow{2}{*}{ Sex } & Male & 49 & $60.5 \%$ & 7 & $35.0 \%$ & \multirow{2}{*}{4.22} & \multirow{2}{*}{0.04} \\
\hline & Female & 32 & $39.5 \%$ & 13 & $65.0 \%$ & & \\
\hline \multirow{2}{*}{ Residence } & Urban & 34 & $42.0 \%$ & 9 & $45.0 \%$ & \multirow{2}{*}{0.06} & \multirow{2}{*}{0.81} \\
\hline & Rural & 47 & $58.0 \%$ & 11 & $55.0 \%$ & & \\
\hline \multirow{2}{*}{ Education } & Literate & 53 & $65.4 \%$ & 10 & $50.0 \%$ & \multirow{2}{*}{1.63} & \multirow{2}{*}{0.20} \\
\hline & illiterate & 28 & $34.6 \%$ & 10 & $50.0 \%$ & & \\
\hline \multirow{5}{*}{$\begin{array}{l}\text { Socioeconomic } \\
\text { status }\end{array}$} & class I & 22 & $27.2 \%$ & 8 & $40.0 \%$ & \multirow{5}{*}{1.98} & \multirow{5}{*}{0.57} \\
\hline & class II & 45 & $55.6 \%$ & 9 & $45.0 \%$ & & \\
\hline & class III & 11 & $13.6 \%$ & 3 & $15.0 \%$ & & \\
\hline & class IV & 3 & $3.7 \%$ & 0 & $0.0 \%$ & & \\
\hline & class $\mathrm{V}$ & 0 & $0.0 \%$ & 0 & $0.0 \%$ & & \\
\hline \multirow{3}{*}{ Family type } & nuclear & 8 & $9.9 \%$ & 0 & $0.0 \%$ & \multirow{3}{*}{6.15} & \multirow{3}{*}{0.046} \\
\hline & Joint & 59 & $72.8 \%$ & 12 & $60.0 \%$ & & \\
\hline & three generation & 14 & $17.3 \%$ & 8 & $40.0 \%$ & & \\
\hline \multirow{4}{*}{$\begin{array}{l}\text { Systolic Blood } \\
\text { Pressure }\end{array}$} & normal BP & 36 & $44.4 \%$ & 6 & $30.0 \%$ & \multirow{4}{*}{9.64} & \multirow{4}{*}{0.02} \\
\hline & pre hypertension & 39 & $48.1 \%$ & 8 & $40.0 \%$ & & \\
\hline & stage I & 5 & $6.2 \%$ & 6 & $30.0 \%$ & & \\
\hline & stage II & 1 & $1.2 \%$ & 0 & $0.0 \%$ & & \\
\hline \multirow{4}{*}{$\begin{array}{l}\text { Diastolic Blood } \\
\text { Pressure }\end{array}$} & normal BP & 12 & $14.8 \%$ & 2 & $10.0 \%$ & \multirow{4}{*}{5.24} & \multirow{4}{*}{0.15} \\
\hline & pre hypertension & 38 & $46.9 \%$ & 6 & $30.0 \%$ & & \\
\hline & stage I & 28 & $34.6 \%$ & 9 & $45.0 \%$ & & \\
\hline & stage II & 3 & $3.7 \%$ & 3 & $15.0 \%$ & & \\
\hline & underweight & 11 & $13.6 \%$ & 0 & $0.0 \%$ & & \\
\hline BMI & normal range & 35 & $43.2 \%$ & 7 & $35.0 \%$ & & \\
\hline BIVII & overweight & 20 & $24.7 \%$ & 3 & $15.0 \%$ & 10.06 & 0.02 \\
\hline & Obese & 15 & $18.5 \%$ & 10 & $50.0 \%$ & & \\
\hline RBS & $<140$ & 75 & $92.6 \%$ & 15 & $75.0 \%$ & 512 & בחת \\
\hline KDS & $>140$ & 6 & $7.4 \%$ & 5 & $25.0 \%$ & 0.12 & 0.02 \\
\hline
\end{tabular}


Table 3.Binary regression for IRDS score and it's associate odd's for obesity, HTN and T2DM

\begin{tabular}{|c|c|c|c|c|c|}
\hline \multirow{2}{*}{ Independent variables } & \multirow{2}{*}{ B } & \multirow{2}{*}{ Sig. } & \multirow{2}{*}{ Adjusted odds } & \multicolumn{2}{|c|}{ 95\% C.I. for EXP (B) } \\
\cline { 5 - 6 } & & & & Lower & Upper \\
\hline HTN & 0.713 & 0.04 & 2.04 & 1.01 & 4.10 \\
\hline BMI & 0.742 & 0.01 & 2.09 & 1.21 & 3.63 \\
\hline RBS & 1.427 & 0.03 & 4.16 & 1.12 & 15.44 \\
\hline
\end{tabular}

On univariate analysis sociodemographic factors like increased age, female sex and persons from three-generation families reported stronger risk, and so also high systolic BP, $\mathrm{BMI}$ and RBS. These details are presented in Table 2.

On bivariate analysis, it was found that the participants with high IDRS score had higher odd's for developing obesity, systolic BP and diabetes. This is presented in Table 3.

The sensitivity and specificity if IDRS in detecting diabetes was subjected to ROC curve analysis. The area under the curve was $70 \%$ and for a cut-off score of 35(in moderate risk zone) IDRS recorded a sensitivity of $90 \%$ and specificity of $64 \%$. Figure 1 presents the results of the ROC curve in this regards.

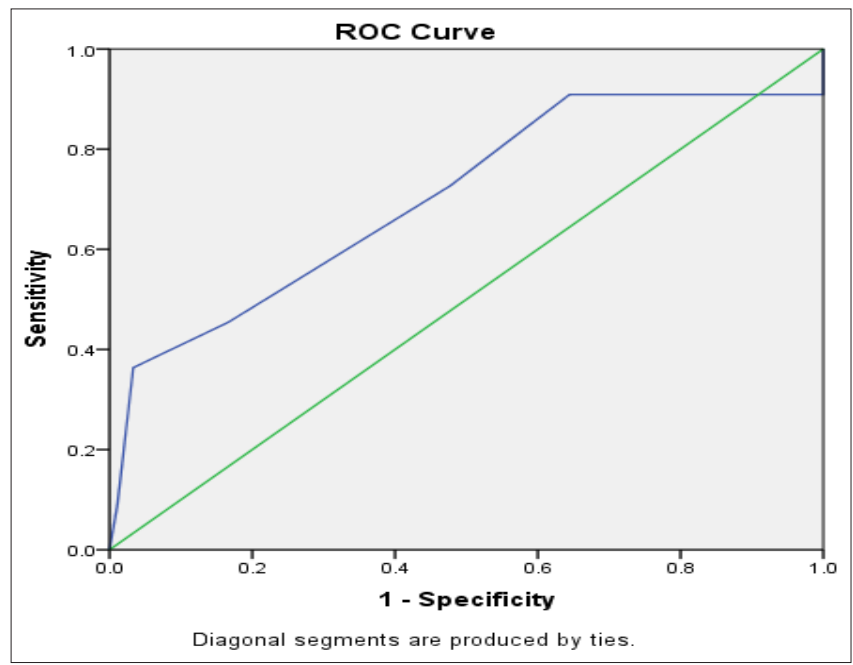

Figure I.The ROC curve for IDRS for detecting its sensitivity and specificity

\section{Discussion}

In order to tame the menace of diabetes proactive screening is the need of the hour. The designed tool should be simple to carry out, cost-effective and noninvasive in nature. This should also be geo-cultural sensitive and specific. The Indian Diabetes Risk Score (IDRS) is one such tool designed specifically for the Indian population which gives more weightage to ethnic risks like measurements for detection of truncal obesity. ${ }^{11}$ It has two modifiable and two nonmodifiable screeners. The modifiable ones are abdominal obesity and physical activity and the nonmodifiable ones are age and family history. This simple to use instrument is user-friendly and can be carried out at the community level by a health worker or any literate motivated personnel with minimal training. ${ }^{13}$

Using IDRS, about $19.8 \%$ of participants were detected to have high risk, $55.4 \%$ at moderate risk and $24.8 \%$ at low risk for developing diabetes. Dugg et al in their study on 185 adults reported a risk prevalence of $49.2 \%, 46.5 \%$, and $4.3 \%$ respectively for high risk, moderate risk and low risk for developing diabetes. ${ }^{14}$ Bala et al also observed similar risks in their study. ${ }^{15}$ The studies using IRDS by Panda et al and Khandhedia et al had results closer to ours with the high-risk prevalence at $17.9 \%$ and $22.8 \%$ respectively. ${ }^{16,17}$

In the present study, IDRS was significantly higher in patients with advanced age group, females, members of the threegeneration family, hypertensive and obese individuals $(p<0.05)$. Association of age and IDRS could be explained by the fact that IDRS scoring depends upon age. Dugg et al also observed similar findings i.e. on univariate analysis, the female had high IDRS as compared to the males. ${ }^{14}$ Dudeja et al observed a significant association between risk factors for diabetes like age, family history, waist circumference, waist-hip ratio and occurrence of diabetes. ${ }^{18}$

In our study, hypertensive participants, High BMI candidates and persons with RBS over $140 \mathrm{mg} / \mathrm{dl}$ were reported to have increased odd's of higher IDRS score. These findings are supported by various other studies in which odds of developing diabetes were higher in individuals with higher BMI $\left(>25 \mathrm{~kg} / \mathrm{m}^{2}\right)$ and raised BP. ${ }^{13,17,18}$ The possible explanation could be rapid urbanization, with its consequent lifestyle transitions like the shift from manual work to less physically active jobs, the dietary transition from traditional Indian diet to the western diet, high in fat, refined sugar and processed foods with added preservatives etc. Subjects with high IDRS regardless of their blood sugar status, are ideal candidates for lifestyle modification as these are risk factors for not only diabetes but also for cardiovascular disease.

Receiver Operating Characteristic [ROC] curve was constructed to identify the optimum value of IDRS for detecting diabetes. The Area Under the Curve (AUC) was in the acceptable range at 0.704 with a $95 \%$ confidence interval (Cl) of 0.518-0.889 and a p-value of 0.028 (supplementary table 1). An IDRS value of $\geq 35$ was selected from 'Coordinates of the Curve' that had an optimum sensitivity of $90.9 \%$ 
and specificity of $64.4 \%$ (supplementary table 2 ). Mohan $V$ et al. and Dudeja $P$ et al. had similar observation but for a coordinate value of $\geq 60 .{ }^{13,18}$ We suppose we could have improved the accuracy by enrolling a bigger population.

\section{Conclusion}

This study highlights the importance of screening program for early identification of diabetes. The study also suggests that IDRS can be considered as a cost-effective, simple, noninvasive and fairly accurate tool for screening of diabetes in undiagnosed individuals attending premier hospitals on a routine basis; thereby enhancing the domain for detecting diabetes and helping them in getting early treatment. However, at the same time, we would like to adopt caution regarding its generalizability, which should be established by more extensive and multicentre studies.

\section{Study High Light}

Every opportunity should be explored especially at health care setups, by socio-cultural and ethnic-specific, easy to administer, noninvasive, and cost and empirically productive screen tools to detect diabetes in the undetected population.

\section{Acknowledgement}

We are thankful to all the study participants for their willful participants and the medical interns who were of great help in data collection. A special thanks to the hospital authorities for extending their kind cooperation.

\section{Conflict of Interest: None}

\section{References}

1. Mohan V, Deepa R, Deepa M et al. A Simplified Indian Diabetes Risk Score for Screening for Undiagnosed Diabetic Subjects. J Assoc Physicians India 2005; 53: 755-763.

2. World Health Day (WHO). Available at: http://www. searo.Who.int/entity/India/mediacentre/ events/2016/ en. Accessed on 28 December 2019.

3. Roglic G. WHO Global report on diabetes: A summary. International Journal of Noncommunicable Diseases. 2016; 1(1): 3. Available at: http:// apps.who.int/iris/ bitstream/10665/204871/1/9789241565257_eng.pdf. Accessed on 10 December 2019.

4. India country report 2017. The International Diabetes Federation Diabetes Atlas. 8th ed. Available from: www. diabetesatlas.org.

5. Adhikari P, Pathak R, Kotian S. Validation of the MDRF Indian Diabetes Risk Score (IRDS) in another South Indian population through the Boloor Diabetes Study (BDS). J Assoc Physicians India 2010; 58: 434-436.

6. Mohan V, Sandeep S, Deepa R, Shah B, Varghese C. Epidemiology of type 2 diabetes: Indian scenario. Indian J Med Res 2007; 125(3): 217-230.

7. Herman WH, Ye W, Griffin SJ, Simmons RK, Davies MJ,
Khunti K et al. Early detection and treatment of type 2 diabetes reduce cardiovascular morbidity and mortality: a simulation of the results of the Anglo-Danish-Dutch Study of Intensive Treatment in People With ScreenDetected Diabetes in Primary Care (ADDITION-Europe). Diabetes care. 2015; 38(8): 1449-1455.

8. Premalatha G, Shanthirani S, Deepa R, Markovitz J, Mohan V. Prevalence and risk factors of peripheral vascular disease in a selected South Indian population: the Chennai Urban Population Study. Diabetes care 2000; 23(9): 1295-1300.

9. Mucheria VN. Prevalence and risk factors of peripheral vascular disease in diabetic foot lesions. IJSS 2016; 3(11): 32-36.

10. American Diabetes Association. Screening for diabetes. Diabetes care. 2002; 25(suppl 1): s21-4.

11. Lee CM, Colagiuri S. Risk scores for diabetes prediction: the International Diabetes Federation PREDICT-2 project. Diabetes Res Clin Pract 2013; 100(2): 285-286.

12. Mohan D, Guha PR, Rema M, Anjana M, Deepa R, Shanthirani Setal. The Chennai Urban Rural Epidemiology Study (CURES)-study design and methodology (urban component) (CURES-1). The Journal of the Association of Physicians of India 2003 51; 863-870.

13. Mohan V, Deepa R, Deepa M, Somannavar S, Datta, M. A simplified Indian diabetes risk score for screening for undiagnosed diabetic subjects. Journal of the Association of Physicians of India 2005; 53: 759-763.

14. Dugg $P$, Cherian V, Upadhyay MK. Opportunistic screening for diabetes using Indian diabetes risk Score among patients aged 30 years and above attending rural health training center in Delhi. Int J Med Sci Public Health 2019; 8(4): 264-269.

15. Bala S, Pandve H, Kamala K, Dhanalakshmi A, Sarikonda $\mathrm{H}$. Performance of Indian diabetic risk score as a screening tool of diabetes among women of industrial urban area. J Family Med Prim Care 2019; 8: 3569-3573.

16. Panda PS, Jain K, Soni GP, Gupta SA, Chandrakar A, Pradhan SK. Screening for risk of diabetes among adult population of Raipur city using Indian diabetic risk score. Int J Med Sci Public Health 2017; 6: 1038-1041.

17. Khandhedia SA, Chaudhary AI, Unadkat S, Parmar D. A study on assessment of risk of developing diabetes using IDRS (Indian diabetes risk score) in the urban area of Jamnagar city. Sch J Appl Med Sci 2015; 3: 2358-2360.

18. Dudeja P, Singh G, Gadekar T, Mukherji S. Performance of Indian diabetes risk score (IDRS) as screening tool for diabetes in an urban slum. Medical Journal Armed Forces India 2017; 73(2): 123-128. 


\section{Supplementary Tables}

Table I

\begin{tabular}{|c|c|c|c|}
\hline \multicolumn{5}{|c|}{ Area Under the Curve } \\
\hline \multirow{2}{|c|}{ Area } & Std. Error ${ }^{\text {a }}$ & Asymptotic Sig. & Tesult Variable (s): totalscore \\
\cline { 3 - 4 } & .095 & .028 & Asymptotic 95\% Confidence Interval \\
\hline 0.704 & Lower Bound & .518 & Upper Bound \\
\hline The test result variable(s): total score has at least one tie between the positive actual state group and the negative \\
actual state group. Statistics may be biased.
\end{tabular}

Table 2

\begin{tabular}{|c|c|c|}
\hline \multicolumn{3}{|c|}{ Coordinates of the Curve } \\
\hline \multicolumn{3}{|c|}{ Test Result Variable (s): IDRS Score } \\
\hline Positive if Greater Than or Equal To ${ }^{\mathrm{a}}$ & Sensitivity & 1 - Specificity \\
\hline 9.00 & 1.000 & 1.000 \\
\hline 15.00 & .909 & 1.000 \\
\hline 25.00 & .909 & .733 \\
\hline 35.00 & .909 & .644 \\
\hline 45.00 & .727 & .478 \\
\hline 55.00 & .455 & .167 \\
\hline 65.00 & .364 & .033 \\
\hline 75.00 & .091 & .011 \\
\hline 81.00 & .000 & .000 \\
\hline
\end{tabular}

